\title{
Adherence in adults with type I diabetes mellitus correlates with treatment satisfaction but not with adverse events
}

This article was published in the following Dove Press journal:

Patient Preference and Adherence

29 August 2013

Number of times this article has been viewed

\author{
Tereza Hendrychova' \\ Magda Vytrisalova' \\ Alena Smahelova ${ }^{2}$ \\ Jiri Vlcek' \\ Ales Antonin Kubena' \\ 'Department of Social and Clinical \\ Pharmacy, Faculty of Pharmacy in \\ Hradec Králové, Charles University \\ in Prague, Hradec Králové, Czech \\ Republic; ${ }^{2}$ Diabetes Center, \\ Department of Gerontology and \\ Metabolism, University Hospital \\ and Faculty of Medicine in Hradec \\ Králové, Charles University in Prague, \\ Hradec Králové, Czech Republic
}

Correspondence: Tereza Hendrychova Department of Social and Clinical Pharmacy, Faculty of Pharmacy in Hradec Králové, Charles University in Prague, Heyrovskeho I203, 50005 Hradec Králové, Czech Republic

Tel +420 49506729 I

Fax +420 495 512266

Email terhen@centrum.cz
Purpose: Diabetes self-care and self-monitoring adherence has a positive effect on the metabolic control of the disease. The aim of this study was to analyze the adherence to self-care recommendations and to identify its correlates in adults with type 1 diabetes mellitus.

Patients and methods: One hundred and eleven patients with type 1 diabetes were enrolled in an observational cross-sectional study conducted at the Diabetes Center of the University Hospital in Hradec Králové, Czech Republic. Diabetes self-care adherence was measured by the Self Care Inventory-Revised, and treatment satisfaction by the Diabetes Treatment Satisfaction Questionnaire-status version. Additional data were collected from self-administered questionnaires and medical records. The Mann-Whitney test, Spearman correlations, and multiple linear regressions were used in the statistical analysis.

Results: The mean age of patients was 42.4 years; $59.5 \%$ of them were females and $53.2 \%$ of all patients used an insulin pump. The mean glycosylated hemoglobin $\left(\mathrm{HbA}_{1 \mathrm{c}}\right)$ was $66.2 \pm 15.3 \mathrm{mmol} / \mathrm{mol}$ and the mean insulin dosage was $0.6 \pm 0.3 \mathrm{IU}$ insulin $/ \mathrm{kg} /$ day. The number of hypoglycemic episodes (including severe) that patients had in the last month before taking the survey was $3.6 \pm 3$.2. Self-care adherence was associated with treatment satisfaction $(0.495 ; P=0.004)$ along with frequency of self-monitoring of before meal blood glucose $(0.267$; $P=0.003)$. It was not associated with the incidence of hypoglycemic events or any other insulin therapy-related problems or with socio-demographic or clinical characteristics.

Conclusion: Treatment satisfaction is one of the key factors that need to be targeted to maximize benefits to patients. Self-care adherence in adults with type 1 diabetes did not correlate with socio-demographic and clinical characteristics, nor with adverse events.

Keywords: treatment adherence, self-care inventory revised, diabetes treatment satisfaction questionnaire, self-monitoring

\section{Introduction}

Type 1 diabetes mellitus requires continual intensive treatment in order to reduce the risk and progression of chronic micro- and macro-vascular complications. ${ }^{1}$ On the other hand, the treatment of the condition is associated with a high risk of acute complications, particularly hypoglycemia. ${ }^{2}$ The prevention and control of both types of complications are significantly influenced by adherence to treatment. The multiple lifestyle modifications that are of utmost importance in the management of diabetes require a high degree adherence from the patients as well. ${ }^{3}$

Adherence is defined as the extent to which a person's behavior (taking medication, making lifestyle modifications) corresponds with the agreed recommendations from a health care provider. ${ }^{4}$ Adherence to the treatment of chronic diseases is customarily 
poor and as such negatively influences both effectiveness in routine clinical practice as well as the efficacy outcomes of various therapeutic methods in clinical trials. ${ }^{5-9}$ The correlations between adherence and clinical outcomes of patients with both types of diabetes were analyzed in one review $\operatorname{article}^{10}$ which, like another study, ${ }^{3}$ has shown the positive effect of adherence on metabolic control in adults with type 1 diabetes.

A number of factors affecting adherence to treatment in different clinical situations have been identified. To promote adherence in routine clinical practice, those intuitive, unambiguously detectable and closely associated with attitudes toward treatment are of key relevance. One of the most suggestible factors influencing adherence may be treatment satisfaction. ${ }^{11}$

Since positive correlates in one population may represent negative ones in other populations, ${ }^{7}$ it is important to study the relation in a specific clinical context. Little attention has as of yet been devoted to adherence regarding the treatment of type 1 diabetes. To our knowledge, the possible association between adherence and socio-demographic and/or clinical characteristics based on observational data taken from routine practice and attitudinal factors has not yet been adequately investigated in adults with type 1 diabetes. The available studies are related mainly to children and adolescents, ${ }^{12-15}$ with a number of these ${ }^{14,15}$ suggesting certain positive, especially psychological, correlates of higher adherence. Kyngäs and Rissanen ${ }^{14,15}$ have stated that support from health care providers and relatives as well as overall motivation, willpower, and threat to the physical wellbeing of the patient were predictors of good adherence. These results, however, cannot be generalized to adult patients with type 1 diabetes, as adherence may vary during the lifetime depending on the formation of the personality, including the attitude towards treatment. ${ }^{16}$ The previously mentioned review ${ }^{11}$ dealing with the relationship between adherence and treatment satisfaction included only one study with type 1 diabetes, and, further, this was not conducted in adults only and used a non-validated questionnaire to assess satisfaction. Consequently, we feel that the relationship between adherence and treatment satisfaction in adults with type 1 diabetes merits further investigation.

With reference to type 1 diabetes management, the term adherence is now often specified by the expressions self-care adherence or self-management adherence to correspond better with the comprehensive nature of the tasks to be mastered by the patient on an everyday basis in order to control the disease and to reach therapeutic goals. ${ }^{17,18}$
Overall, the aim of this study was to analyze adherence to self-care recommendations and to identify specific correlates in patients with this condition. The results of investigations into these relationships could aid healthcare providers in the estimation of the adherence of their patients. Those with potentially lower adherence might be provided with additional support specifically tailored to individual needs, the effect of which could improve treatment outcomes.

\section{Methods}

An observational cross-sectional study was conducted in the Diabetes Center of the University Hospital in Hradec Králové, Czech Republic, from September to December 2010. The study design was approved by the regional Ethics Committee and conforms to the provisions of the Declaration of Helsinki.

\section{Study population}

On randomly selected days, all patients with type 1 diabetes who had appointments at the outpatient clinic of the Diabetes Center were addressed, and those who met the entry criteria, agreed to fill out the questionnaire and were willing to provide their informed consent to use their medical records were enrolled in the study. The entry criteria were as follows:

1. Age $\geq 18$ years;

2. partaking in continuous subcutaneous insulin infusion (CSII) therapy or multiple daily injections (MDI) therapy for $\geq$ last 12 months;

3. in females, no pregnancy during the last 12 months;

4. no acute comorbidity.

MDI therapy was defined as three or more daily insulin injections.

Of $132(100 \%)$ patients addressed, 123 (93\%) agreed to participate in the study. Twelve of these were excluded from the study due to a failure to meet the entry criteria, thus a total of $111(84 \%)$ patients were enrolled.

\section{Questionnaires}

Questionnaires were self-administered by previously instructed patients during routine follow-up visits to the Diabetes Center. To collect the basic socio-demographic data and health and clinical characteristics, two different versions of the questionnaire were used, one for the patients on CSII and another for those on MDI therapy. The following two types of basic data were obtained, the first from all patients involved in the study (a), and the second measuring 
other data related to period of the most recent therapeutic regimen (b):

a1. Socio-demographic characteristics (sex, age, level of education, number of inhabitants in the city of residence, social status);

a2. health characteristics (diabetes duration, smoking habits);

b1. frequency of routine self-monitoring of blood glucose (BG) and blood pressure;

b2. incidence of adverse events during treatment (hypoglycemia, adverse reaction at the insulin injection site, problems with use of insulin pump or insulin pen). The questionnaires are available on request.

Both the CSII and MDI groups of patients were administered the Self-Care Inventory-Revised (SCI-R) (La Greca; 2005) ${ }^{19}$ and the Diabetes Treatment Satisfaction Questionnaire-status version (DTSQs) (Bradley; 1994). ${ }^{20}$ The DTSQs was available in the linguistically validated Czech version which suitability we corroborated with Cronbach's $\alpha$ of 0.86 . The SCI-R was translated into Czech and validated with a Cronbach's $\alpha$ of 0.73 . To ensure the quality of the SCI-R in Czech, forward-backward translation was performed by two independent translators.

All tools used and the study design were discussed with clinicians. Prior to starting data collection, a pilot study was conducted with ten type 1 diabetes patients.

\section{Data derived from medical records}

1. Nature and duration of current insulin therapy;

2. basal and bolus insulin type and usual dose (patients are routinely advised to adjust doses of insulin according to their daily regime and BG level by health care providers);

3. other prescription medications used;

4. clinical parameters (height, weight, glycosylated hemoglobin, and blood pressure) based on at least two measurements performed within the last 12 months (including measurements taken on the day the questionnaires were filled out). These measurements were then averaged for each respondent.

\section{Outcome measures}

\section{Adherence to self-care recommendations (SCl-R)}

To evaluate the adherence to self-care recommendations, the SCI-R ${ }^{19,21}$ was used. This protocol assesses patients' perceptions of the degree to which they have adhered to the recommendations for their diabetes self-care in the past 1-2 months. The form includes 15 questions that can be categorized into the following groups: BG regulation (two questions); insulin and food regulation (eight questions); exercise (one question), and emergency precautions (three questions). One question is related to routine follow-up visits to the treatment center. Some questions deal with several of these subject areas. The SCI-R answers are scored on a five-point Likert scale (never, rarely, sometimes, usually, always; 1-5 points, respectively). The output of the questionnaire is a numerical score, with a higher score indicating a higher adherence to self-care recommendations. The complete questionnaire and questionnaire manual are available in electronic form. ${ }^{19,22}$

\section{Satisfaction with treatment (DTSQs)}

The DTSQs ${ }^{20}$ is a specific tool to measure satisfaction with treatment in patients with type 1 and 2 diabetes. It includes eight items, with answers scored from 0 (very dissatisfied) to 6 (very satisfied). The questions are related; for example, for treatment flexibility, the degree of the patient's satisfaction in terms of understanding diabetes as well as the likelihood of the patient recommending the treatment to another person with similar manifestations of the disease. The total score is a sum of six individual item scores. A higher total score indicates a higher satisfaction with treatment. Two questions related to the perceived frequency of hyper- and hypoglycemic events are assessed separately. Patients who indicated an unacceptably high or low BG level most of the time were instructed to mark 6 and those who never experienced such feelings to mark 0 . The questionnaire manual is available in electronic form. ${ }^{23}$

\section{Statistical analysis}

Statistical analysis was performed using the PASW 18.0 software (version 18.0, IBM Corporation, Armonk, NY, USA). A $P$-value of $<0.05$ was considered statistically significant. Data are summarized as the mean $( \pm$ standard deviation $[\mathrm{SD}])$, median, or range for continuous variables, and percentages for categorical variables. Differences in patient characteristics between the two treatment regimens were compared using the $\chi^{2}$ test for categorical variables and the Mann-Whitney $U$ test for continuous variables.

To investigate associations with the adherence score (continuous variable), the Mann-Whitney test was used for dichotomous variables and Spearman correlations were used for continuous variables. Multiple linear regression was employed to identify independent variables associated with adherence. All variables with a statistically significant association with the adherence score in the previous analyses were included in the regression analysis. Clinical relevance 
of the effect was assessed by means of $\eta^{2}$. The limits between categories were taken from the Cohen convention. ${ }^{24}$

\section{Results}

\section{Characteristics of patients}

The socio-demographic characteristics of the study population are presented in Table 1. Almost no differences in basic socio-demographic characteristics were found between the CSII group and MDI group, save for the finding that MDI patients reported a larger number of inhabitants in the city of residence $(P<0.01)$.

Clinical characteristics of the study population are summarized in Table 2. Patients receiving the CSII therapy were more often treated with insulin analogues, with lower bolus and total insulin doses (IU/kg/day), as well as used more boluses during the day ( $P \leq 0.001$ for each factor). At the same time, these patients have a higher average body mass index (BMI) than patients undergoing MDI therapy $(P<0.01)$. A higher incidence of difficulties with the device for the application of insulin was reported by insulin pump users than by insulin pen users $(P=0.011)$.

\section{Self-monitoring frequency}

Patients on CSII therapy performed self-monitoring of fasting BG $(P<0.05)$ and before meal BG $(P<0.01)$ more often. The two groups did not differ in the frequency of self-monitoring of other types of BG (Table 3 ).

\section{Self-care adherence}

The patients studied most often failed to comply with the recommendations for keeping food records and checking ketones when their glucose level was high. The highest adherence level was reported by the patients for keeping clinic appointments/having phone contact with the doctor, and taking the correct dose of insulin. The SCI-R mean individual and total scores are given in Table 4 . The adherence scores did not differ between the CSII and MDI patients.

The significant associations between adherence and other variables for the total cohort are summarized in Table 5. Significant results of the subsequent multiple analyses for the total cohort are shown in Table 6.

\section{Satisfaction with treatment}

The mean DTSQs total score $( \pm S D)$ of the whole study cohort, CSII group, and MDI group was $29.6 \pm 5.3$; $30.4 \pm 4.0 ; 28.6 \pm 6.4$, respectively ( 36.0 being the maximum possible score). The mean scores for the questions related to the perceived frequency of hyper- and hypoglycemia were $2.3 \pm 1.3$ and $2.0 \pm 1.3 ; 2.4 \pm 1.4$ and $2.0 \pm 1.2 ; 2.3 \pm 1.3$ and $2.1 \pm 1.4$, respectively $(0=$ never; $6=$ most of the time $)$.

Table I Socio-demographic characteristics of the study cohort

\begin{tabular}{|c|c|c|c|}
\hline Characteristic & Total cohort $(\mathbf{N}=I I I)$ & CSII group $(N=59)$ & MDI group $(N=52)$ \\
\hline Age & $N=\| I I$ & $N=59$ & $N=52$ \\
\hline (years; mean \pm SD; range) & $42.4 \pm 13.8 ; 19-77$ & $42.1 \pm 12.6 ; 19-65$ & $42.8 \pm 15.1 ; 19-77$ \\
\hline Sex & $N=I I I$ & $N=59$ & $N=52$ \\
\hline Male (\%) & 40.5 & 44.1 & 36.5 \\
\hline Female (\%) & 59.5 & 55.9 & 63.5 \\
\hline Education & $N=\| 11$ & $N=59$ & $N=52$ \\
\hline Primary and lower secondary (\%) & 6.3 & 6.8 & 5.8 \\
\hline Apprenticeship training (\%) & 36.9 & 40.7 & 32.7 \\
\hline Upper secondary (\%) & 41.4 & 39.0 & 44.2 \\
\hline Tertiary (\%) & 15.3 & 13.6 & 17.3 \\
\hline Size of the place of residence by population** & $N=110$ & $N=58$ & $N=52$ \\
\hline 10,000 or less $(\%)$ & 56.4 & 69.0 & 42.3 \\
\hline $10,000-50,000(\%)$ & 15.5 & 8.6 & 23.1 \\
\hline $50,000-100,000(\%)$ & 22.7 & 20.7 & 25.0 \\
\hline 100,000 or more $(\%)$ & 5.5 & 1.7 & 9.6 \\
\hline Economic status & $N=109$ & $N=58$ & $N=5 I$ \\
\hline Student (\%) & 5.5 & 3.5 & 7.8 \\
\hline Employee (\%) & 61.5 & 62.1 & 60.8 \\
\hline Old age pensioner (\%) & 13.8 & 13.8 & 13.7 \\
\hline Disability pensioner (\%) & 19.3 & 20.7 & 17.6 \\
\hline Living alone & $N=\| 11$ & $N=59$ & $N=52$ \\
\hline Yes (\%) & 6.3 & 1.7 & 11.5 \\
\hline No $(\%)$ & 93.7 & 98.3 & 88.5 \\
\hline
\end{tabular}

Note: **The difference between MDI and CSII group is highly statistically significant $(P<0.0 \mathrm{I})$.

Abbreviations: $\mathrm{N}$, number of subjects; CSII, continuous subcutaneous insulin infusion; MDI, multiple daily injections; SD, standard deviation. 
Table 2 Clinical characteristics of the study cohort

\begin{tabular}{|c|c|c|c|}
\hline Clinical parameter & Total cohort $(\mathrm{N}=|\mathrm{I}| \mathrm{I})$ & CSII group $(N=59)$ & MDI group $(N=52)$ \\
\hline Diabetes duration & $N=110$ & $N=59$ & $N=5 I$ \\
\hline (years; mean $\pm S D$; range) & $19.2 \pm 11.1 ; 2-53$ & $20.27 \pm 10.4 ; 4-53$ & $18.0 \pm 12.0 ; 2-45$ \\
\hline CSIl duration & $N=57$ & $N=57$ & - \\
\hline (months; mean $\pm \mathrm{SD}$; range) & $66.4 \pm 58.3 ; 2-53$ & $66.4 \pm 58.3 ; 2-53$ & - \\
\hline Smoking & $N=87$ & $N=44$ & $N=43$ \\
\hline Nonsmoker (\%) & 78.2 & 77.3 & 79.1 \\
\hline Occasional smoker (\%) & 12.6 & $1 \mathrm{l} .4$ & 14.0 \\
\hline Regular smoker (\%) & 9.2 & 11.4 & 7.0 \\
\hline \multicolumn{4}{|l|}{ Treatment with insulin } \\
\hline Type of insulin** & $N=\| I I$ & $N=59$ & $N=52$ \\
\hline Insulin analogue (\%) & 80.2 & 93.2 & 65.4 \\
\hline Human insulin (\%) & 19.8 & 6.8 & 34.6 \\
\hline Total insulin dose** & $N=110$ & $N=58$ & $N=52$ \\
\hline$(\mathrm{IU} / \mathrm{kg} /$ day; mean $\pm \mathrm{SD})$ & $0.6 \pm 0.3$ & $0.6 \pm 0.2$ & $0.7 \pm 0.3$ \\
\hline Basal insulin dose & $N=110$ & $N=58$ & $N=52$ \\
\hline (IU/kg/day; mean \pm SD) & $0.3 \pm 0.1$ & $0.3 \pm 0.1$ & $0.3 \pm 0.1$ \\
\hline Bolus insulin dose** & $N=110$ & $N=59$ & $N=5 I$ \\
\hline (IU/kg/day; mean $\pm \mathrm{SD}$ ) & $0.3 \pm 0.2$ & $0.2 \pm 0.1$ & $0.4 \pm 0.2$ \\
\hline Number of boluses/day & $N=I I I$ & $N=59$ & $N=52$ \\
\hline$($ mean $\pm S D)$ & $3.4 \pm 0.9$ & $3.7 \pm 1.2$ & $3.1 \pm 0.3$ \\
\hline Number of concomitant Rx drugs & $N=67$ & $N=33$ & $N=34$ \\
\hline$($ mean $\pm S D)$ & $3.2 \pm 2.8$ & $3.4 \pm 3.0$ & $3.0 \pm 2.8$ \\
\hline $\begin{array}{l}\text { Adjusting the doses of insulin according } \\
\text { to daily regime and BG level }\end{array}$ & $N=102$ & $N=57$ & $N=45$ \\
\hline Yes $(\%)$ & 97.1 & 98.2 & 95.6 \\
\hline No $(\%)$ & 2.9 & 1.8 & 4.4 \\
\hline \multicolumn{4}{|l|}{ Biochemical and clinical measures } \\
\hline $\mathrm{HbA}_{\mathrm{Ic}}$ & $N=I I I$ & $N=59$ & $N=52$ \\
\hline$(\mathrm{mmol} / \mathrm{mol} ;$ mean $\pm \mathrm{SD})$ & $66.2 \pm 15.3$ & $65.5 \pm 14.2$ & $67.0 \pm 16.5$ \\
\hline $\mathrm{BMI} * *$ & $N=109$ & $N=59$ & $N=50$ \\
\hline$\left(\mathrm{kg} / \mathrm{m}^{2} ;\right.$ mean $\left.\pm \mathrm{SD}\right)$ & $25.4 \pm 3.9$ & $26.4 \pm 3.8$ & $24.2 \pm 3.8$ \\
\hline Blood pressure & $N=109$ & $N=57$ & $N=52$ \\
\hline$(\mathrm{mmHg} ;$ mean $\pm \mathrm{SD})$ & $129.0 \pm 9.8 / 77.9 \pm 5.7$ & $129.8 \pm 10.1 / 78.4 \pm 5.5$ & $128.0 \pm 11.7 / 77.9 \pm 5.9$ \\
\hline \multicolumn{4}{|l|}{ Adverse events } \\
\hline Number of hypoglycemic episodes ${ }^{a}$ & $N=104$ & $N=56$ & $N=48$ \\
\hline \multicolumn{4}{|l|}{ in the last month (including severe) } \\
\hline$($ mean $\pm S D)$ & $3.6 \pm 3.2$ & $4.0 \pm 2.9$ & $3.3 \pm 3.5$ \\
\hline Severe hypoglycemia ${ }^{b}$ in the last month & $N=105$ & $N=58$ & $N=47$ \\
\hline Yes (\%) & 6.7 & 3.4 & 10.6 \\
\hline No $(\%)$ & 93.3 & 96.6 & 89.4 \\
\hline Adverse reaction at the insulin injection site & $N=107$ & $N=58$ & $N=49$ \\
\hline Yes (\%) & 59.8 & 63.8 & 55.1 \\
\hline No $(\%)$ & 40.2 & 36.2 & 44.9 \\
\hline Problems with insulin pump or insulin pen* & $N=105$ & $N=58$ & $N=48$ \\
\hline Yes (\%) & 48.1 & 67.2 & 25.0 \\
\hline No $(\%)$ & 51.9 & 32.8 & 75.0 \\
\hline
\end{tabular}

Notes: ${ }^{a}$ Blood glucose $\leq 3.5 \mathrm{mmol} / \mathrm{L}$; blood glucose $\leq 2.0 \mathrm{mmol} / \mathrm{L}$; *the difference between MDI and CSIl group is statistically significant $(P<0.05)$; $* *$ the difference between $\mathrm{MDI}$ and CSII group is highly statistically significant $(P<0.0 \mathrm{I})$.

Abbreviations: BG, blood glucose; BMI, body mass index; CSII, continuous subcutaneous insulin infusion; HbA $\mathrm{A}_{\mathrm{Ic}}$ glycosylated hemoglobin according to International Federation of Clinical Chemistry; MDI, multiple daily injections; N, number of subjects; SD, standard deviation.

The treatment satisfaction scores did not differ significantly between the CSII and MDI patients.

\section{Discussion}

To our knowledge, adherence correlates in patients with type 1 diabetes have not yet been studied to an extent as in the present study. Focusing on associations between adherence and a range of various factors, our work showed that adherence to self-care recommendations in adult patients with type 1 diabetes correlated with treatment satisfaction and did not correlate with socio-demographic and clinical characteristics based on observational data taken from routine practice. 
Table 3 Frequency of routine self-monitoring of blood glucose and blood pressure in the study cohort

\begin{tabular}{|c|c|c|c|}
\hline Self-monitored parameter & Total cohort $(\mathbf{N}=I I I)$ & CSII group $(N=59)$ & MDI group $(N=52)$ \\
\hline Fasting BG/week* & $N=75$ & $N=4 I$ & $N=34$ \\
\hline$($ mean $\pm S D)$ & $4.4 \pm 2.3$ & $4.8 \pm 2.0$ & $3.9 \pm 2.5$ \\
\hline Before meal BG/week** & $N=77$ & $N=43$ & $N=34$ \\
\hline$($ mean $\pm S D)$ & $9.5 \pm 8.4$ & $11.5 \pm 8.2$ & $7.1 \pm 8.1$ \\
\hline After meal BG/week & $N=77$ & $N=43$ & $N=34$ \\
\hline$($ mean $\pm S D)$ & $5.9 \pm 5.9$ & $6.6 \pm 5.5$ & $5.0 \pm 6.2$ \\
\hline Before sleep BG/week & $N=10 I$ & $N=57$ & $N=44$ \\
\hline$($ mean $\pm S D)$ & $4.2 \pm 2.5$ & $4.5 \pm 2.4$ & $3.7 \pm 2.6$ \\
\hline Between midnight and $4 \mathrm{am} \mathrm{BG} /$ month & $N=78$ & $N=43$ & $N=35$ \\
\hline$($ mean $\pm S D)$ & $3.4 \pm 4.0$ & $3.3 \pm 2.3$ & $3.4 \pm 5.4$ \\
\hline "Small BG profile"a/month & $N=82$ & $N=44$ & $N=38$ \\
\hline$($ mean $\pm S D)$ & $4.0 \pm 4.4$ & $4.1 \pm 3.7$ & $4.0 \pm 5.2$ \\
\hline "Big BG profile"b/month & $N=106$ & $N=58$ & $N=48$ \\
\hline$($ mean $\pm S D)$ & $3.1 \pm 3.5$ & $3.0 \pm 2.4$ & $3.2 \pm 4.5$ \\
\hline Blood pressure/year & $N=103$ & $N=57$ & $N=46$ \\
\hline (mean $\pm \mathrm{SD} ;$ median) & $46.0 \pm 132 ; 12$ & $28.1 \pm 58.3 ; 12$ & $68.1 \pm 185.3 ; 12$ \\
\hline
\end{tabular}

Notes: ${ }^{a}$ Fasting BG, BG I-hour after lunch, I-hour after dinner and before sleep; bfasting BG, BG I-hour after breakfast, before lunch, I-hour after lunch, before dinner, I-hour after dinner and before sleep; *the difference between MDI and CSII group is statistically significant $(P<0.05)$; **the difference between MDI and CSII group is highly statistically significant $(P<0.01)$.

Abbreviations: BG, blood glucose; CSII, continuous subcutaneous insulin infusion; MDI, multiple daily injections; N, number of subjects; SD, standard deviation.

The highest rates of adherence were found in the areas of insulin therapy (administration of the correct insulin dose at the right time), keeping routine clinic appointments, and carrying quick-acting sugar. Despite the fact that patients often indicated "usually" or "always" when answering the items

Table 4 Adherence to treatment according to SCI-R

\begin{tabular}{|c|c|c|c|}
\hline & $\begin{array}{l}\text { Total cohort } \\
(\mathbf{N}=\text { III })\end{array}$ & $\begin{array}{l}\text { CSII } \\
(N=59)\end{array}$ & $\begin{array}{l}\text { MDI } \\
(N=52)\end{array}$ \\
\hline SCl-R total score $($ mean $\pm S D)$ & $57.1 \pm 6.7$ & $57.6 \pm 6.3$ & $56.5 \pm 7$ \\
\hline Glucose testing & $4.2 \pm 0.7$ & $4.3 \pm 0.7$ & $4.1 \pm 0.7$ \\
\hline Glucose recording & $3.9 \pm 1.0$ & $3.9 \pm 0.9$ & $3.8 \pm 1.0$ \\
\hline Ketone testing & $2.2 \pm 1.3$ & $2.4 \pm 1.3$ & $2.1 \pm 1.3$ \\
\hline $\begin{array}{l}\text { Administering correct } \\
\text { insulin dose }\end{array}$ & $4.6 \pm 0.5$ & $4.6 \pm 0.5$ & $4.7 \pm 0.5$ \\
\hline $\begin{array}{l}\text { Administering insulin } \\
\text { at right time }\end{array}$ & $4.5 \pm 0.6$ & $4.4 \pm 0.6$ & $4.5 \pm$ \\
\hline Correct food portions & $4.1 \pm 0.6$ & $4.1 \pm 0.6$ & $4.1 \pm 0.7$ \\
\hline Eating meals on time & $4.1 \pm 0.8$ & $4.2 \pm 0.9$ & $4.1 \pm 0$. \\
\hline Keeping food records & $1.9 \pm 1.0$ & $1.9 \pm 1.0$ & $1.9 \pm 1$ \\
\hline Reading food labels & $3.4 \pm 1.2$ & $3.4 \pm 1.2$ & $3.4 \pm 1$ \\
\hline $\begin{array}{l}\text { Proper treatment } \\
\text { of low blood glucose }\end{array}$ & $3.7 \pm 1.1$ & $3.8 \pm 1.0$ & $3.7 \pm 1$ \\
\hline Carrying quick-acting sugar & $4.5 \pm 1.0$ & $4.6 \pm 0.8$ & $4.4 \pm 1.1$ \\
\hline $\begin{array}{l}\text { Coming in for appointments/ } \\
\text { phone contact with the } \\
\text { physician }\end{array}$ & $4.7 \pm 0.8$ & $4.7 \pm 0.8$ & $4.7 \pm 1.0$ \\
\hline Wearing a medical alert ID & $4.0 \pm 1.5$ & $4.1 \pm 1.4$ & $3.8 \pm 1.6$ \\
\hline Exercising & $3.3 \pm 1.1$ & $3.2 \pm 1.1$ & $3.3 \pm 1.0$ \\
\hline Proper insulin adjustment & $4.2 \pm 0.9$ & $4.3 \pm 0.9$ & $4.2 \pm 1$ \\
\hline
\end{tabular}

Abbreviations: $\mathrm{N}$, number of subjects; CSII, continuous subcutaneous insulin infusion; MDI, multiple daily injections; SCI-R, Self Care Inventory-Revised (total score range $=15-75$; five-point Likert scale: never - rarely - sometimes usually - always; I-5 points); SD, standard deviation; ID, identification. related to compliance with correct food portions and eating meals on time, in practice patients generally failed to comply with the recommendations for keeping food records. Patients more often answered "never" or "rarely" when asked about the ketone testing while they were hyperglycemic. Relatively low scores were given by the patients even to the items regarding reading food labels and glucose recording. These results are in accordance with the data reported by La Greca (available online); $;^{22}$ our outcomes are not fully comparable, however, since the revised version of the SCI-R questionnaire was used in our study. Ruggiero et $\mathrm{a}^{17}$ and Broadbent et $\mathrm{a}^{25}$ have reported lower adherence to diet and exercise than to medication in both type 1 and 2 diabetes patients. This conclusion is consistent with the results obtained in

Table 5 Significant associations between adherence (SCl-R score) and other variables for total cohort $(\mathrm{N}=\mathrm{III})$

\begin{tabular}{lll}
\hline $\begin{array}{l}\text { SCI-R score } \\
\text { correlated with }\end{array}$ & $\begin{array}{l}\text { Correlation coefficient } \\
\text { Spearman's rho }\end{array}$ & $\begin{array}{l}\text { Significance } \\
(\boldsymbol{P} \text {-value })\end{array}$ \\
\hline $\begin{array}{l}\text { Education } \\
\text { Satisfaction with treatment } \\
\text { (DTSQs score) }\end{array}$ & 0.216 & 0.027 \\
$\begin{array}{l}\text { Frequency of self-monitoring } \\
\text { of before meal BG }\end{array}$ & 0.325 & 0.020 \\
$\begin{array}{l}\text { Frequency of self-monitoring } \\
\text { of blood pressure }\end{array}$ & 0.200 & 0.004 \\
$\begin{array}{l}\text { Total insulin dose IU/kg/day } \\
\text { Basal insulin dose IU/kg/day }\end{array}$ & -0.238 & 0.047 \\
Sex & -0.214 & 0.015 \\
\hline Abbrevitions SCl-R, Sef Care Inver & 0.029 \\
\hline
\end{tabular}

Abbreviations: SCI-R, Self Care Inventory-Revised; DTSQs, Diabetes Treatment and Satisfaction Questionnaire status version; BG, blood glucose. 
Table 6 Significant associations between adherence and other variables in multiple analysis for the total cohort $(\mathrm{N}=\mathrm{II} \mathrm{I})$

\begin{tabular}{llll}
\hline Factors $^{\mathrm{a}}$ & $\begin{array}{l}\text { Regression } \\
\text { coefficient B }\end{array}$ & $\begin{array}{l}\text { Significance } \\
(\boldsymbol{P} \text {-value })\end{array}$ & $\begin{array}{l}\text { Effect } \\
\text { size }\left(\eta^{2}\right)\end{array}$ \\
\hline $\begin{array}{l}\text { Dependent variable: SCI-R score } \\
\begin{array}{l}\text { Satisfaction with treatment } \\
\text { (DTSQs score) }\end{array}\end{array}$ & 0.495 & 0.004 & $0.119^{\mathrm{b}}$ \\
$\begin{array}{l}\text { Frequency of self-monitoring } \\
\text { of before meal BG }\end{array}$ & 0.267 & 0.003 & $0.126^{\mathrm{b}}$ \\
\hline
\end{tabular}

Notes: aAll variables included in the model were: education; satisfaction with treatment (DTSQs score); frequency of self-monitoring of before meal blood glucose; frequency of self-monitoring of blood pressure; total insulin dose IU/ $/ \mathrm{kg} /$ day; basal insulin dose IU/kg/day; sex; ${ }^{b}$ medium effect size according to the Cohen convention. ${ }^{24}$

Abbreviations: $\mathrm{SCl}-\mathrm{R}$, self-care inventory-revised; DTSQs, diabetes treatment and satisfaction questionnaire status version; BG, blood glucose.

the present study. Relatively high scores given to the core questionnaire items may reflect the high quality of education provided to patients in the Diabetes Center which is reflected in their awareness of the importance of adhering to self-care recommendations.

\section{Factors associated with adherence}

One adherence-associated factor seems to be treatment satisfaction. The correlation between these two variables was significant even after adjustment for potential confounders in multiple linear regression. When the score of DTSQs increases by one, the score of SCI-R increases by approximately 0.5 . In the context of various diseases (including diabetes), the correlation has also been confirmed by the previously mentioned review by Barbosa et al. ${ }^{11}$ The scores given regarding adherence and treatment satisfaction in the present study almost did not differ between groups of patients engaging in both types of intensive insulin therapy (IIT). From this, it can be inferred that if both types of IIT are available to the patient (see below), he/she is as likely to be satisfied with or adherent to either of them as not to be. Treatment satisfaction in CSII therapy does not seem to be negatively influenced by a higher frequency of self-monitoring of morning fasting and before meal BG. Significant differences between CSII and MDI therapies in type 1 diabetes patients measured by the DTSQs have also not been reported by other studies. ${ }^{26,27}$ On the other hand, an extensive case-control study by Dutch author ${ }^{28}$ has reported different results, ie, a higher treatment satisfaction in patients on CSII therapy. Treatment satisfaction should not be confused with quality of life which is more influenced by the impact of the disease and its treatment on a wide range of areas of patient's life. Quality of life, which has often been reported as poor despite high treatment satisfaction, ${ }^{29}$ was not measured in the present study.
In the total cohort, a highly significant correlation was found between adherence and the frequency of self-monitoring of before meal BG; this was found even after adjustment for potential confounders in multiple linear regression. When the frequency of self-monitoring of before meal BG increases by one per week, the score of SCI-R increases by approximately 0.3 . Patients on CSII therapy reported that they performed self-monitoring of before meal BG significantly more often than those on MDI therapy. This finding was confirmed by Hoogma et al, ${ }^{26}$ who compared the frequency of BG self-monitoring under different IIT regimens. Being aware of before meal BG levels is critical to the calculation of bolus insulin dosage for type 1 diabetes patients; on the other hand, patients on CSII therapy likely appreciate that insulin pump therapy allows for more flexibility in lifestyle. To obtain the maximum benefit from the insulin pump, an optimal adherence to self-monitoring of BG is crucial. We found no other study that focused on the correlation between frequency of BG self-monitoring and adherence to self-care recommendations in type 1 diabetes patients.

\section{Factors not correlated with adherence}

Adherence did not correlate with socio-demographic characteristics, which is somewhat in accordance with a 1991 critical review on diabetes self-management. ${ }^{30}$ In the present study, correlation analysis found no correlation between adherence nor underlying disease control assessed by glycosylated hemoglobin $\left(\mathrm{HbA}_{1 c}\right)$. As for type 1 diabetes, it must be pointed out that $\mathrm{HbA}_{1 \mathrm{c}}$ values are significantly influenced not only by adherence to treatment modalities, but also by diabetes duration, psycho-social status and genetic factors. ${ }^{12,18}$ In contrast to other chronic diseases, ${ }^{31,32}$ adherence in adults with type 1 diabetes did not correlate with adverse events during treatment. This finding is considered as positive and may be a result of the intensive and high-quality education provided to patients of the Diabetes Center. This diabetes education is tailored to individual needs and is repeated as often as required. The emphasis placed on gaining knowledge and skills makes patients aware of the need for the treatment of their disease, and thus promotes adherence to self-care recommendations despite the treatment-associated problems that may arise.

\section{Strengths and limitations of the study}

A major positive of the present study is that it was conducted under conditions of real clinical practice in a particular Diabetes Center, thus avoiding the influence of the possible variations in the selection of patients for CSII, patient 
education or treatment modalities. Also, a relatively high number of patients (111) were enrolled in the study, with both types of IIT being evenly represented. The two groups of patients did not differ in most basic demographic and clinical characteristics. The differences in the total daily insulin dose (IU/kg/day) and BMI between the study groups are in accordance with the results of meta-analyses ${ }^{33-35}$ that compared the clinical outcomes of each type of IIT; these differences are due to the nature of the regimens. Patients on insulin pump therapy, which allows for more flexibility in lifestyle, use lower bolus and total daily insulin doses and a higher number of daily boluses. These individuals eat more meals during the day, which may result in a slight weight (BMI) gain, as is often observed when a patient switches to CSII therapy. The higher percentage of patients on CSII with insulin analogues in comparison with MDI also reflects real conditions of clinical practice. The homogeneity of the study cohort is also supported by the fact that it only includes adult patients with type 1 diabetes. Patients on CSII may differ from those on MDI in some psychological characteristics and abilities. ${ }^{36}$ These characteristics make them suitable candidates for a particular type of therapy and, at the same time, may significantly influence their self-care adherence. Nevertheless, patients on CSII and MDI did not significantly differ in adherence or treatment satisfaction, thus the correlates of adherence were assessed in the study cohort as a whole.

Another advantage of the present study was our use of high-quality and validated assessment tools. ${ }^{19,20}$ The significant correlation between adherence and frequency of selfmonitoring of before meal BG confirms the appropriateness of the adherence questionnaire used in the present study.

A limitation of the present study is that a self-report method was used to evaluate both adherence as well as the frequency of blood glucose self-monitoring. This might have biased the results, eg, due to the tendency of respondents to present themselves in the best possible light (social desirability bias). Self-reports have been widely used in adherence studies as an inexpensive and time saving tool, and when patients are asked about specific activities and the extent to which these are performed, as is the case in the present study, ${ }^{21}$ more reliable results are usually reported. ${ }^{16}$

Moreover, the present study focused on adherence to self-care recommendations, which is to say not only to drug therapy, for example. When the results were processed the total score was always used despite the fact that results from different areas of adherence to self-care recommendations may relate to other factors. Consequently, this approach to measuring the multifaceted nature of diabetes self-care may not be sensitive enough. ${ }^{16}$ The total score from the adherence assessment scale was used based on the factorial analysis of results, a fact which demonstrated that the scale as a whole has sufficient internal consistency (Cronbach's $\alpha 0.73$ ), and does not contain any item which could have been removed to further increase it. Hence, a single-factor model was used in the present study. Moreover, according to Rabiau et al, ${ }^{37}$ non-adherence in one area may be coupled with better adherence to other self-care recommendations (compensatory beliefs). Patients with equal total scores in different adherence assessment tools may vary regarding the extent to which they adhere to various self-care items, and this fact may not influence the results; eg, of the evaluation of adherence correlates. This assumption needs to be tested in more detail.

As indicated above, the present study did not take into account psychiatric comorbidities that may significantly influence adherence. ${ }^{38,39}$ Information about psychiatric therapy, if any, was derived from the records of other prescription drugs used, but such comprehensive records were available for only a small proportion of the study patients, thus a more detailed analysis was not feasible. For the same reason, it was not possible to analyze the relationship between chronic complications of diabetes and adherence. The medical records in each respective area were not standard enough to avoid biasing the results.

Similarly to other studies, another source of bias could be in the selective enrolment of patients who were more motivated to adhere to self-care recommendations than those who declined to fill in the questionnaires. Nevertheless, the proportion of patients who declined to participate was low (7\%) and as such was unlikely to be a significant limitation.

\section{Recommendations for future studies in this area}

As stated in the preceding section, it would be better to obtain objective data about the adherence or frequency of blood glucose self-monitoring (downloads from the patients' meters, for instance). Further, we would in addition suggest a study of adherence in patients with type 1 diabetes who are being treated with different modalities, as there could be diverse associations resulting from psychological characteristics as well as abilities in which patients may differ. Then again, higher numbers of patients would be required for such studies. Longitudinal data would be necessary to confirm the results of the current study. 


\section{Conclusion}

The present study showed that self-care adherence is associated with treatment satisfaction in adult patients with type 1 diabetes. We found out a strong correlation between frequency of self-monitoring of before meal BG and adherence. Adherence to self-care recommendations in adults with type 1 diabetes did not correlate with sociodemographic and clinical characteristics or with adverse events. When monitoring self-care adherence in patients with type 1 diabetes, physicians should question patients about their level of treatment satisfaction in order to target possible reasons for non-satisfaction.

\section{Acknowledgments}

This study was supported by research grant No SVV 267005 from Charles University in Prague, Czech Republic. Access to DTSQ: The DTSQ is available from http://www. healthpsychologyresearch.com.

\section{Disclosure}

The authors report no conflicts of interest in this work.

\section{References}

1. American Diabetes Association. Standards of medical care in diabetes2011. Diabetes Care. 2011;34 Suppl 1:S11-S61.

2. Cryer PE. Hypoglycaemia: the limiting factor in the glycaemic management of Type I and Type II diabetes. Diabetologia. 2002;45(7): 937-948.

3. Toljamo M, Hentinen M. Adherence to self-care and glycaemic control among people with insulin-dependent diabetes mellitus. J Adv Nurs. 2001;34(6):780-786.

4. Sabate E, editor. Adherence to Long-Term Therapies: Evidence for Action. Geneva: World Health Organization; 2003.

5. Larsen J, Stovring H, Kragstrup J, Hansen DG. Can differences in medical drug compliance between European countries be explained by social factors: analyses based on data from the European Social Survey, round 2. BMC Public Health. 2009;9:145.

6. Simpson SH, Eurich DT, Majumdar SR, et al. A meta-analysis of the association between adherence to drug therapy and mortality. BMJ. 2006;333(7557):15.

7. Cramer JA, Benedict A, Muszbek N, Keskinaslan A, Khan ZM. The significance of compliance and persistence in the treatment of diabetes, hypertension and dyslipidaemia: a review. Int J Clin Pract. 2008;62(1): 76-87.

8. Hughes DA, Bagust A, Haycox A, Walley T. The impact of noncompliance on the cost-effectiveness of pharmaceuticals: a review of the literature. Health Econ. 2001;10(7):601-615.

9. Boudes P. Drug compliance in therapeutic trials: a review. Control Clin Trials. 1998;19(3):257-268.

10. Asche C, LaFleur J, Conner C. A review of diabetes treatment adherence and the association with clinical and economic outcomes. Clin Ther. 2011;33(1):74-109.

11. Barbosa CD, Balp MM, Kulich K, Germain N, Rofail D. A literature review to explore the link between treatment satisfaction and adherence, compliance, and persistence. Patient Prefer Adherence. 2012;6:39-48.

12. Hood KK, Peterson CM, Rohan JM, Drotar D. Association between adherence and glycemic control in pediatric type 1 diabetes: a metaanalysis. Pediatrics. 2009;124(6):e1171-e1179.
13. Naar-King S, Idalski A, Ellis D, et al. Gender differences in adherence and metabolic control in urban youth with poorly controlled type 1 diabetes: the mediating role of mental health symptoms. J Pediatr Psychol. 2006;31(8):793-802.

14. Kyngas H, Rissanen M. Support as a crucial predictor of good compliance of adolescents with a chronic disease. J Clin Nurs. 2001;10(6): 767-774.

15. Kyngäs HA. Predictors of good adherence of adolescents with diabetes (insulin-dependent diabetes mellitus). Chronic Illn. 2007;3(1): 20-28.

16. Johnson SB. Methodological issues in diabetes research. Measuring adherence. Diabetes Care. 1992;15(11):1658-1667.

17. Ruggiero L, Glasgow RE, Dryfoos JM, et al. Diabetes self-management: Self-reported recommendations and patterns in a large population. Diabetes Care. 1997;20(4):568-576.

18. Guo J, Whittemore R, He GP. The relationship between diabetes selfmanagement and metabolic control in youth with type 1 diabetes: an integrative review. J Adv Nurs. 2011;67(11):2294-2310.

19. La Greca A. The Self Care Inventory-Revised. Miami: University of Miami, Department of Psychology; 2005. Available from: http://www. psy.miami.edu/faculty/alagreca/SCI-R.pdf. Accessed May 21, 2012.

20. Bradley C. Diabetes treatment satisfaction questionnaire. In: Bradley C, editors. Handbook of Psychology and Diabetes: A Guide to Psychological Measurement in Diabetes Research and Practice. Harwood Academic Publisher: Chur; 1994:111-132.

21. Weinger K, Butler HA, Welch GW, La Greca AM. Measuring diabetes self-care: a psychometric analysis of the Self-Care Inventory-Revised with adults. Diabetes Care. 2005;28(6):1346-1352.

22. La Greca A. Manual for the Self Care Inventory. Miami; University of Miami, Department of Psychology; 2004. Available from: http:// www.psy.miami.edu/faculty/alagreca/SCI_manual_2004.pdf. Accessed May 21, 2012

23. Bradley C. DTSQs and DTSQc User Guidelines. London: Royal Holloway University of London, Health Psychology Research; 2010. Available from: http://www.healthpsychologyresearch.com/Admin/ uploaded/Guidelines/dtsqs\&cuser guidelines_rev.17.3.10.pdf. Accessed May 21, 2012.

24. Cohen J. A power primer. Psychol Bull. 1992;112(1):155-159.

25. Broadbent E, Donkin L, Stroh JC. Illness and treatment perceptions are associated with adherence to medications, diet, and exercise in diabetic patients. Diabetes Care. 2011;34(2):338-340

26. Hoogma RP, Spijker AJ, van Doorn-Scheele M, et al. Quality of life and metabolic control in patients with diabetes mellitus type 1 treated by continuous subcutaneous insulin infusion or multiple daily insulin injections. Neth J Med. 2004;62(10):383-387.

27. DeVries JH, Snoek FJ, Kostense PJ, Masurel N, Heine RJ; Dutch Insulin Pump Study Group. A randomized trial of continuous subcutaneous insulin infusion and intensive injection therapy in type 1 diabetes for patients with long-standing poor glycemic control. Diabetes Care. 2002;25(11):2074-2080.

28. Nicolucci A, Maione A, Franciosi M, et al; EQuality1 Study Group Evaluation of QUALITY of Life and Costs in Diabetes Type 1. Quality of life and treatment satisfaction in adults with Type 1 diabetes: a comparison between continuous subcutaneous insulin infusion and multiple daily injections. Diabet Med. 2008;25(2):213-220.

29. Bradley C, Speight J. Patient perceptions of diabetes and diabetes therapy: assessing quality of life. Diabetes Metab Res Rev. 2002; 18 Suppl 3:S64-S69.

30. Goodall TA, Halford WK. Self-management of diabetes mellitus: a critical review. Health Psychol. 1991;10(1):1-8.

31. Dibonaventura M, Gabriel S, Dupclay L, Gupta S, Kim E. A patient perspective of the impact of medication side effects on adherence: results of a cross-sectional nationwide survey of patients with schizophrenia. BMC Psychiatry. 2012;12:20.

32. Miyachi Y, Hayashi N, Furukawa F, et al. Acne management in Japan: study of patient adherence. Dermatology (Basel). 2011;223(2): $174-181$. 
33. Weissberg-Benchell J, Antisdel-Lomaglio J, Seshadri R. Insulin pump therapy: a meta-analysis. Diabetes Care. 2003;26(4):1079-1087.

34. Retnakaran R, Hochman J, DeVries JH, et al. Continuous subcutaneous insulin infusion versus multiple daily injections: the impact of baseline A1c. Diabetes Care. 2004;27(11):2590-2596.

35. Pickup J, Mattock M, Kerry S. Glycaemic control with continuous subcutaneous insulin infusion compared with intensive insulin injections in patients with type 1 diabetes: meta-analysis of randomised controlled trials. BMJ. 2002;324(7339):705.

36. Lenhard MJ, Reeves GD. Continuous subcutaneous insulin infusion: a comprehensive review of insulin pump therapy. Arch Intern Med. 2001;161(19):2293-2300.
37. Rabiau MA, Knäuper B, Nguyen TK, Sufrategui M, Polychronakos C. Compensatory beliefs about glucose testing are associated with low adherence to treatment and poor metabolic control in adolescents with type 1 diabetes. Health Educ Res. 2009;24(5):890-896.

38. Nau DP, Aikens JE, Pacholski AM. Effects of gender and depression on oral medication adherence in persons with type 2 diabetes mellitus. Gend Med. 2007;4(3):205-213.

39. Gehi A, Haas D, Pipkin S, Whooley MA. Depression and medication adherence in outpatients with coronary heart disease: findings from the Heart and Soul Study. Arch Intern Med. 2005;165(21):2508-2513.

\section{Publish your work in this journal}

Patient Preference and Adherence is an international, peer-reviewed, open access journal focusing on the growing importance of patient preference and adherence throughout the therapeutic continuum. Patient satisfaction, acceptability, quality of life, compliance, persistence and their role in developing new therapeutic modalities and compounds to optimize clinical outcomes for existing disease states are major areas of interest. This journal has been accepted for indexing on PubMed Central. The manuscript management system is completely online and includes a very quick and fair peer-review system. Visit http://www.dovepress.com/ testimonials.php to read real quotes from published authors. 